\title{
Mitochondrially-targeted expression of a cytoplasmic male sterility-associated orf220 gene causes male sterility in Brassica juncea
}

Jinghua Yang ${ }^{1,2}$, Xunyan Liu ${ }^{1,2}$, Xiaodong Yang ${ }^{1,2}$, Mingfang Zhang ${ }^{1,2^{*}}$

\begin{abstract}
Background: The novel chimeric open reading frame (orf) resulting from the rearrangement of a mitochondrial genome is generally thought to be a causal factor in the occurrence of cytoplasmic male sterility (CMS). Both positive and negative correlations have been found between CMS-associated orfs and the occurrence of CMS when CMS-associated orfs were expressed and targeted at mitochondria. Some orfs cause male sterility or semisterility, while some do not. Little is currently known about how mitochondrial factor regulates the expression of the nuclear genes involved in male sterility. The purpose of this study was to investigate the biological function of a candidate CMS-associated orf220 gene, newly isolated from cytoplasmic male-sterile stem mustard, and show how mitochondrial retrograde regulated nuclear gene expression is related to male sterility.

Results: It was shown that the ORF220 protein can be guided to the mitochondria using the mitochondrialtargeting sequence of the $\beta$ subunit of F1-ATPase (atp2-1). Transgenic stem mustard plants expressed the chimeric gene containing the orf220 gene and a mitochondrial-targeting sequence of the $\beta$ subunit of F1-ATPase (atp2-1). Transgenic plants were male-sterile, most being unable to produce pollen while some could only produce nonvigorous pollen. The transgenic stem mustard plants also showed aberrant floral development identical to that observed in the CMS stem mustard phenotype. Results obtained from oligooarray analysis showed that some genes related to mitochondrial energy metabolism were down-regulated, indicating a weakening of mitochondrial function in transgenic stem mustard. Some genes related to pollen development were shown to be downregulated in transgenic stem mustard and the expression of some transcription factor genes was also altered.

Conclusion: The work presented furthers our understanding of how the mitochondrially-targeted expression of CMS-associated orf220 gene causes male sterility through retrograde regulation of nuclear gene expression in Brassica juncea.
\end{abstract}

\section{Background}

Cytoplasmic male sterility (CMS), the maternally inherited trait of failure to produce functional pollen, exists in many plant species and has wide application for the production of hybrid crops. CMS can occur at different stages during reproductive development. It is generally believed that CMS is associated with the rearrangement of mitochondrial genomes, which, in many cases, is attributed to the generation of novel open reading

\footnotetext{
* Correspondence: mfzhang@zju.edu.cn

'Laboratory of Genetic Resources \& Functional Improvement for Horticultural Plants, Department of Horticulture, Zhejiang University, Hangzhou, 310029, P. R. China

Full list of author information is available at the end of the article
}

frames (orfs) [1-5]. Some experimental evidence confirms the correlation between CMS-associated orfs and the occurrence of CMS. In some studies mitochondrially-targeted expression of novel orfs was shown to lead to male sterility or semi-sterility [6-9], while in others it did not [10-12]. A probable interaction between orfB and the ATP synthesis complex in CMS has been demonstrated in sunflower using 2-D electrophoresis and Western blot analysis [13]. However, the specific role of mitochondrial novel orfs in causing male sterility is not yet clearly established and better evidence that mitochondrially-targeted expression of orfs causes male sterility is needed. In particular, how mitochondrial factor regulates the expression of the nuclear genes
Ciomed Central

C 2010 Yang et al; licensee BioMed Central Ltd. This is an Open Access article distributed under the terms of the Creative Commons Attribution License (http://creativecommons.org/licenses/by/2.0), which permits unrestricted use, distribution, and reproduction in any medium, provided the original work is properly cited. 
involved in male sterility is poorly understood. Is there any cross-talk between mitochondria and the nucleus that ultimately determines the abortion of pollen? If so, how do mitochondrial factors directly or indirectly halt the processes of pollen development, and through which pathway?

Recently, many studies have focused on mitochondrial regulation of nuclear gene expression in higher plants [14-18]. This communication pathway from mitochondria to the nucleus is defined as mitochondrial retrograde regulation (MRR), and has been documented mainly in yeast and animals $[19,20]$. Some ABC model genes related to floral organ development, namely the nuclear MADS-box TF genes, have been shown to be targets for floral organ homeotic transformation regulated by MRR [21-26]. In addition, several other nuclear genes have recently been shown to be retrograde regulated by mitochondria in some CMS systems [27-29].

Previously, we isolated the CMS-associated orf 220 gene from CMS stem mustard, Brassica juncea, [30]. In the present study, we constructed transgenic stem mustard expressing the chimeric orf 220 gene mediated by Agrobacterium tumefaciens. These transgenic stem mustard plants exhibited male sterility. Global changes in the expression of mitochondrial and nuclear genes in transgenic stem mustard were examined using oligoarray analysis.

\section{Results}

\section{Chimeric gene construction and transformation of stem} mustard

We had previously isolated the CMS-associated gene, orf220, from CMS stem mustard (Zhang et al., 2003). To verify the function of this gene, a chimeric gene was constructed by fusing orf 220 with a mitochondrialtargeting sequence derived from atp2-1 and amplified from tobacco (Nicotiana plumbaginifolia). The orf 220 gene was amplified from CMS stem mustard and ligated after the mitochondrial-targeting sequence (atp2-1). The chimeric gene was then ligated to the transferred DNA binary vector, $\mathrm{pBI} 121$, driven by the $35 \mathrm{~S}$ promoter. The schematic structure of the chimeric orf 220 gene is shown in Figure 1-A. The constructs were then introduced into A. tumefaciens LBA4404.

The transformation system for stem mustard established in our laboratory is based on a regeneration system from cotyledons with proximal hypocotyls (Figure 1-B). We used this transformation system to produce transgenic stem mustard plants incorporating the alien chimeric orf 220 gene. Candidate transgenic stem mustard plants were checked by PCR and RT-PCR (Figure 1-C) and $5 \mathrm{~T}_{0}$ plants were selected, all exhibiting male sterility. We selected one of these transgenic lines and obtained $28 \mathrm{~T}_{1}$ generation plants, which yielded 13 male-sterile and 15 male-fertile plants. We also used the orf 220 gene as a marker to check that this gene was inherited and could be expressed in $\mathrm{T}_{1}$ transgenic stem mustard. The male-sterile phenotype was shown to be genetically transmitted to the $T_{1}$ generation and associated with orf 220 expression (Figure 1-A). All the 13 male-sterile $\mathrm{T}_{1}$ plants expressed the $\operatorname{orf} 220$ gene, and all the 15 male-fertile $\mathrm{T}_{1}$ plants lacked orf220 expression (data not shown).

We used the chimeric orf 220 gene with GFP expression to check whether this chimeric gene was targeted to the mitochondria. It was shown that the orf 220 gene with the mitochondrial-targeting sequence (atp2-1) was located in the mitochondria, however, the orf 220 gene without the mitochondrial-targeting sequence (atp2-1) was only found in the nucleus (Figure 1-D).

\section{Phenotypes of transgenic stem mustard}

Alterations to the phenotype were observed in transgenic plants in which the chimeric orf 220 gene was expressed. The phenotype was stably inherited between generations. The vegetative growth of transgenic stem mustard was similar to that of WT plants, but their reproductive characteristics differed in numerous ways. Transgenic plants exhibited: 1) 2-3 day delays in bolting and flowering time (Figure 2-A); 2) the appearance of novel, petal-like floral structures at the basal part of the buds (Figure 2-B); and 3) a lack of seed-set suggesting sterility, even though an episperm was observed at an early developmental stage in some siliques (Figure 2-C). When transgenic plants were cross-pollinated with WT pollen, seed-setting occurred indicating normal pistil fertility, and the retention of normal pistil function in transgenic plants (Figure 2-C). Five types of aberrant flowers were observed in transgenic stem mustard: 1 ) flowers with six normal stamens (Figure 2-D2); 2) flowers having two stamens with pollen, and four without pollen (Figure 2-D3); 4) flowers with degenerative stamens devoid of pollen and with crooked pistils (Figure 2-D4, 5); and 5) flowers with a closed corolla and a pistil on the outside (Figure 2-D6). Each transgenic plant bore all five types of aberrant flower. Importantly, the phenotypes of aberrant floral organs in transgenic plants were shown to be identical with those of CMS stem mustard (supplementary data additional file 1 and [31]). The expression of orf 220 without mitochondrial-targeting peptides did not result in a CMS phenotype in Arabidopsis (data not shown).

\section{Activity of pollen produced from transgenic stem mustard}

However, some stamens from transgenic plants can still produce pollen and morphological screening, in vitro germination and in-situ pollen germination were performed to determine the activity of this pollen. The morphology of pollen from transgenic plants was altered 


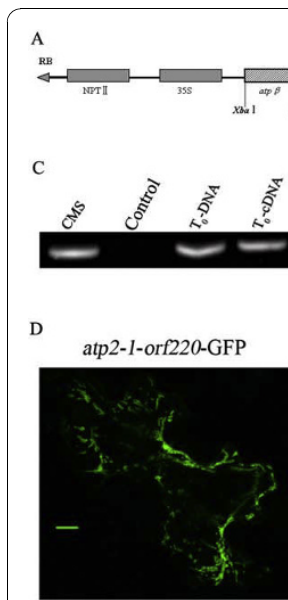

orf220-GFP
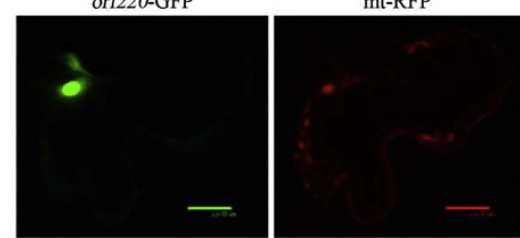

mt-RFP

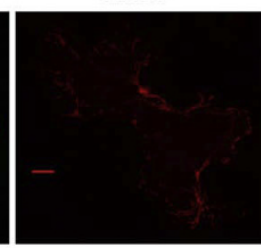

mt-RFP

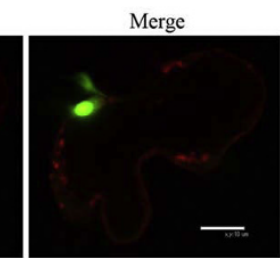

Figure 1 Construction of chimeric orf220 gene, transformation into wild type stem mustard and its sub-localization in mitochondria. Orf220, a candidate cytoplasmic male gene associated with sterility in Brassica juncea, was isolated from cytoplasmic male-sterile stem mustard. A mitochondrial targeted peptide (atp2-1) was isolated from Nicotiana encoding the $\beta$ subunit of F1-ATPase (Figure 1-A). Figure 1-B shows the transgenic regenerations from proximal portions of hypocotyls of cotyledons in stem mustard. Figure 1-C shows the identification of transgenic stem mustard by checking for the presence of the orf220 gene using PCR and RT-PCR. Figure 1-D shows that the mitochondrial targeted peptide (atp2-1) can guide the ORF220 protein to the mitochondria target, while the ORF220 protein is only found in the nucleus in the absence of the mitochondrial targeted peptide (atp21). Mt-RFP was used as the mitochondrially-targeted control.

(Figure 3). While most of the pollen produced by WT plants was susceptible to staining with TTC, some transgenic stem mustard pollen grains resisted staining with TTC, indicating that pollen activity of transgenic plants was markedly different (Figure 3 ). After 4 hrs of in vitro germination, pollen from WT plants was able to produce pollen tubes. However, pollen from transgenic stem mustard failed to germinate (Figure 3). After 12 hrs of in-situ germination on the stigma, fluorescence signals could be detected in pollen from WT plants, but this was not the case for pollen from transgenic stem mustard (Figure 3).

\section{Global gene expression patterns in transgenic and WT stem mustard}

To discover which gene clusters in the mitochondria and nucleus are responsive to mitochondrially-targeted expression of the orf 220 gene, we compared global gene expression patterns between WT and transgenic stem mustard using an oligoarray analysis. Transgenic stem mustard genes that were either down-regulated or upregulated more than two-fold, were selected and sorted according to their cellular components, molecular function and biological processes (Figure 4).

\section{Down-regulated Genes}

Some examples of genes that were down-regulated in transgenic stem mustard are shown in Table 1. A number of mitochondrial genes, such as $\operatorname{cox} 1, \operatorname{cox} 2$ and $\operatorname{atp} 9$, were down-regulated to different degrees in transgenic stem mustard. At2g22080, a gene for a pectate lyase family protein, which is an enzyme involved in the maceration and soft rotting of plant tissue via degradation of the cell wall, was down-regulated more than 8 -fold in transgenic stem mustard. At1g01280 and At1g69500 encode for cytochrome P450 family proteins which function as mono-oxygenases and are involved in hormone, phenolic, alkaloid, sterol and oxygenated fatty acid synthesis. At2g42840 encodes protodermal factor1 (PDF1) protein involved in early meiosis and shoot meristem development. At1g75940 and At3g23770 are male fertility related genes coding for proteins in the glycosyl hydrolase family, with anther-specific expression. At3g11980 is a male-sterile gene, which encodes for male sterility protein $2(M S 2)$, and for a transcriptional factor gene reported to affect pollen development in Arabidopsis. At3g06100, is a gene for a MIP family protein, and is preferentially expressed in the surrounding sporophytic tissues of stamens. At4g12110 encodes a sterol desaturase family protein, which acts as a mediator of fertility. Genes for an ABC transporter family protein (At3g13220), a calcium-binding EF hand family protein (At3g18430) and an alcohol dehydrogenase (At3g42960) were also down-regulated in transgenic stem mustard, as were some genes (At2g42940, At1g76470, At3g07450, At1g20370, At4g30470 and At4g34850) that have been reported to be associated with pollen development. All of the down-regulated genes detected in transgenic plants are listed in supplementary data (additional file 2). The expression of 168 genes was down-regulated in CMS mustard, while 30 genes were down-regulated in transgenic plants, only 17 of these genes being in common (Figure 5).

\section{Up-regulated Genes}

Representative examples of genes that were up-regulated in transgenic stem mustard are shown in Table 2. At2g02930 and At4g25100 encode for glutathione $S$ transferase and superoxide dismutase, respectively, and maintain homeostasis in plant cells. At3g14450 and At3g19090 are thought to code for RNA binding proteins. Some kinase genes were up-regulated (At2g20900, At4g39940, At5g12000 and At4g15530). At3g61890 is a gene for homeobox-leucine zipper protein 12 . 


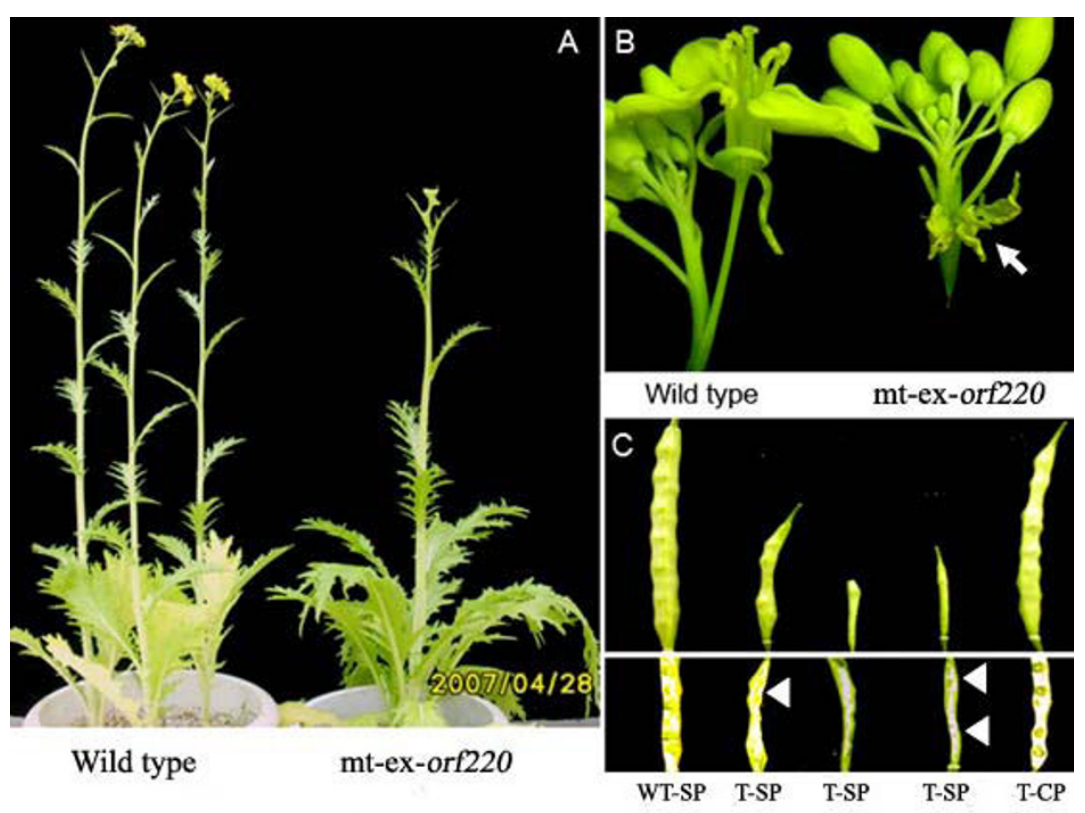

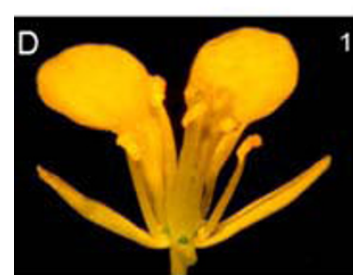

Wild type

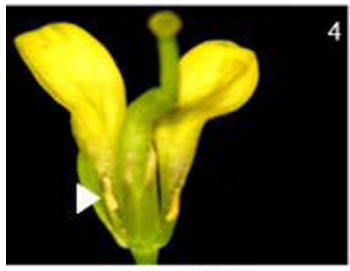

mt-ex-orf 220

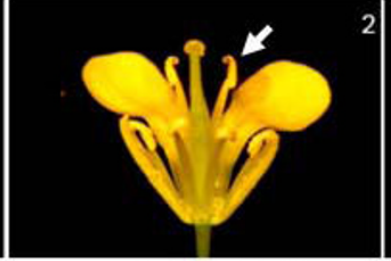

mt-ex-orf 220

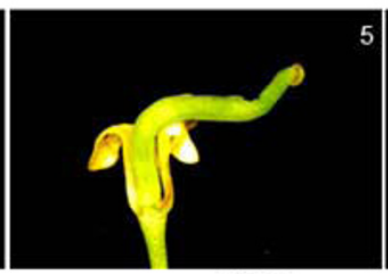

mt-ex-orf 220

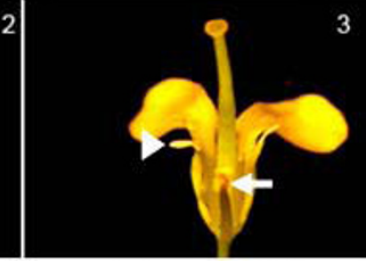

mt-ex-orf 220

3

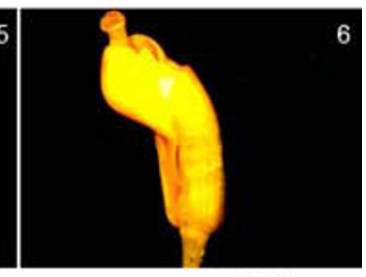

mt-ex-orf 220

Figure 2 Phenotypes of reproductive development in transgenic plants. Delayed flowering of transgenic plants is shown in Figure 2-A. The appearance of novel petal-like floral structures in transgenic plants is shown by an arrow with a hand in Figure 2-B. The time of seed-set of transgenic plants is shown by an arrow without a hand in Figure 2-C. Transgenic plant stamens with pollen are shown by an arrow with a hand, and stamens without by an arrow without a hand in Figure 2-D. WT denotes wild type; mt-ex-orf220 denotes mitochondrial targeted expression of orf220 gene; SP denotes self-pollination; CP denotes cross-pollination with normal pollen.

At5g25560 encodes a zinc finger family protein. Some genes related to metabolism were also up-regulated (At1g78000, At1g32780, At1g14420, At1g12240 and At5g20710), as well as At1g52940, a gene for a calcineurin-like phosphoesterase family protein. All of the up-regulated genes detected in transgenic stem mustard are listed in supplementary data (additional file 3).

\section{Discussion}

The precise mechanism by which mitochondria trigger male sterility is still unknown. It is well known that there is a relationship between novel orfs and the occurrence of CMS, in which orfs play an essential role in disrupting mitochondrial function [1-5]. Meanwhile, several recent studies using cDNA microarrays have identified some nuclear target genes downstream of the pathway of CMS occurrence $[27,28]$. However, the exact mechanism underlying the occurrence of CMS, especially the downstream nuclear target genes and retrograde signaling pathway, remains to be exploited.

The evidence varies as to whether mitochondriallytargeted expression of novel orfs can induce male sterility or not. In some cases this leads to male sterility and in others to semi-sterility [6-9]. However, some mitochondrially-targeted expressions of such novel orfs fail to induce either male sterility or semi-sterility [10-12]. 


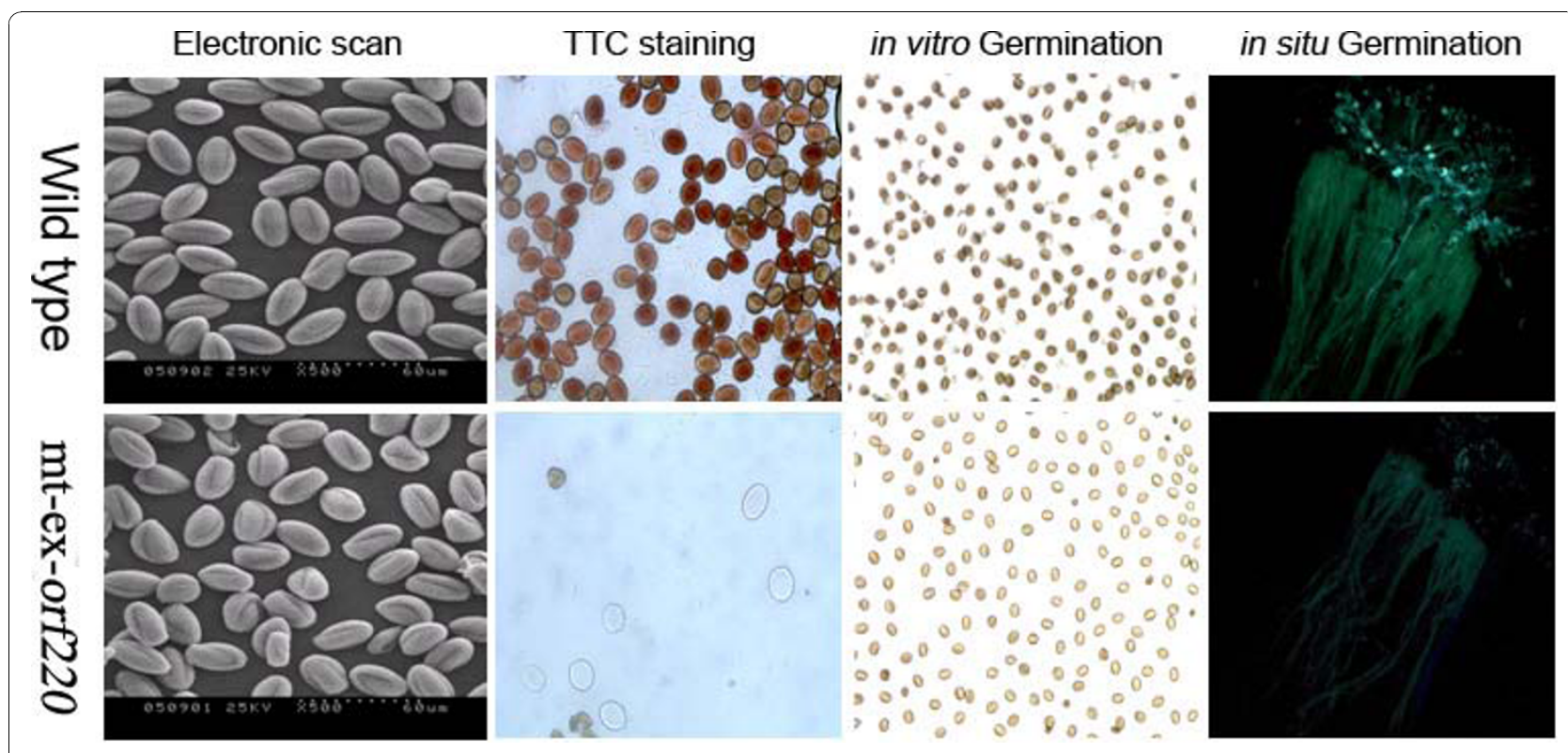

Figure 3 Morphology and activity of pollen produced from transgenic and wild type plants. mt-ex-orf 220 denotes the mitochondrial targeted expression of orf220 gene. TTC denotes 2,3,5-triphenyl-2h-tetrazolium chloride.

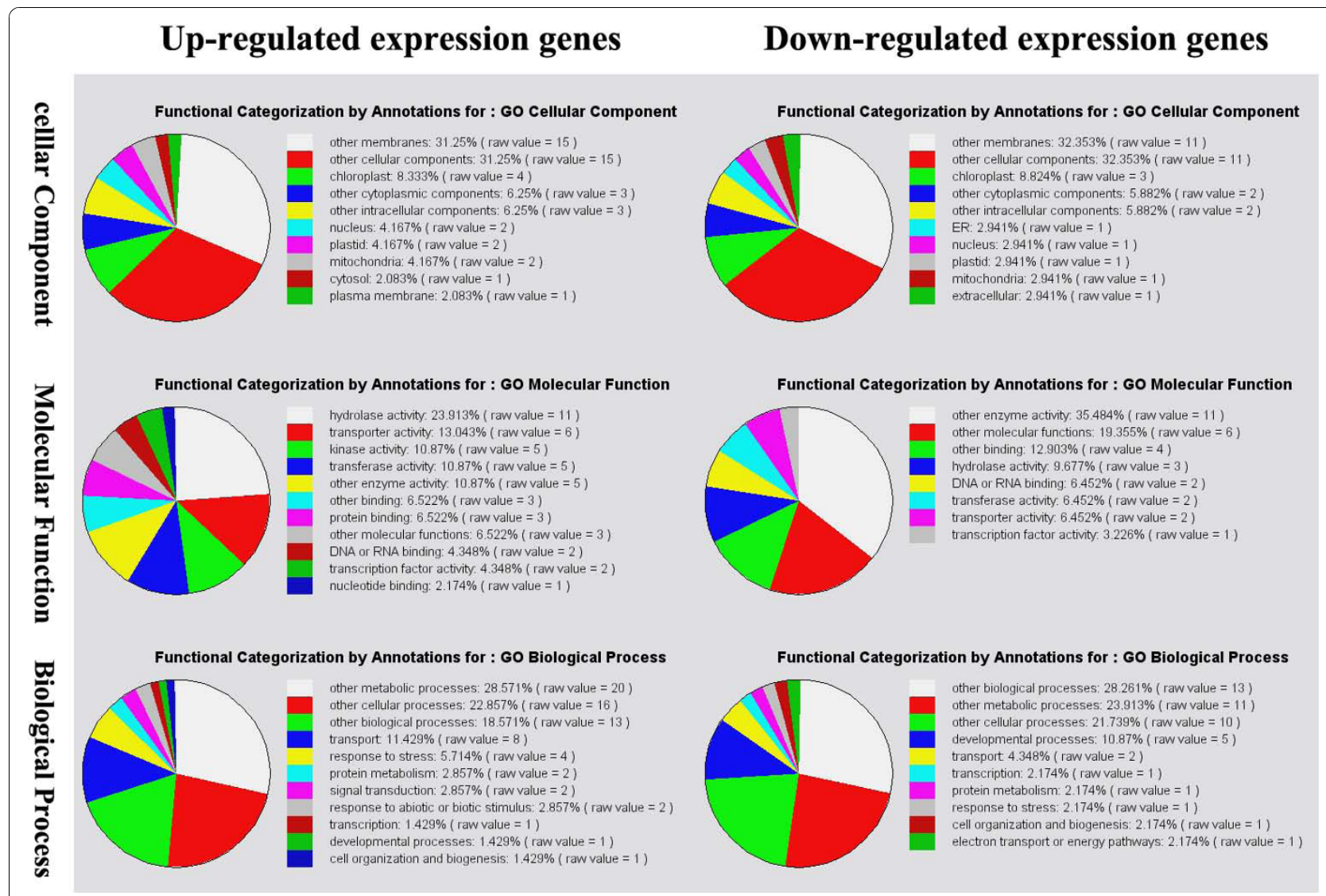

Figure 4 Classification of genes expressed according to their cellular components, molecular function and biological processes in transgenic plants. Up-regulated and down-regulated genes expressed in transgenic stem mustard plants. 
Table 1 Down-regulated expressed genes in transgenic stem mustard observed in this study

\begin{tabular}{lll}
\hline Gene ID & Gene Description & Fold \\
\hline At2g42940 & DNA-binding family protein & 2.5 \\
At2g42840 & protodermal factor 1 (PDF1) & 4.6 \\
At1g75940 & glycosyl hydrolase family 1 protein/anther-specific protein ATA27 & 2.09 \\
At1g01280 & cytochrome P450 family protein & 3.59 \\
At1g76470 & cinnamoyl-CoA reductase family & 3.41 \\
At3g07450 & protease inhibitor/seed storage/lipid transfer protein (LTP) family protein & 2.1 \\
At3g18430 & calcium-binding EF hand family protein & 2.03 \\
At3g13220 & ABC transporter family protein & 3.39 \\
At3g23770 & glycosyl hydrolase family 17 protein & 3.98 \\
At3g11980 & male sterility protein 2 (MS2) & 3.48 \\
At3g06100 & major intrinsic family protein/MIP family protein & 3.51 \\
At1g69500 & cytochrome P450 family protein & 3.89 \\
At1g20370 & tRNA pseudouridine synthase family protein & 2.08 \\
At4g12110 & sterol desaturase family protein & 4.56 \\
At4g22080 & pectate lyase family protein/pectate lyase family protein & 8.66 \\
At4g30470 & cinnamoyl-CoA reductase-related & 2.42 \\
At4g34850 & chalcone and stilbene synthase family protein & 2.79 \\
At3g42960 & alcohol dehydrogenase (ATA1) & 3.62 \\
cox2 & cytochrome c oxidase subunit 2 & \\
cox1 & cytochrome c oxidase subunit 1 & \\
mitochondria.1 & ATP synthase subunit 9 & 2.72 \\
\hline
\end{tabular}

The failure of mitochondria-target expression of novel orfs to induce male sterility is probably due to problems of sub-mitochondrial location [12], the expression period [11] or the expression amount of ORF protein [10] in transgenic plants. In the present study, the reproductive phenotype of transgenic stem mustard was extremely similar to those observed in CMS stem mustard ([31] and supplementary data, Figure 1). From these observations, we concluded that ectopic expression of the chimeric orf 220 gene causes male sterility in transgenic stem mustard. And this could be attributed to direct mitochondrial localization of ORF220 protein guided by a mitochondrial-targeting peptide. In transgenic plants, we observed reduced expressions of several mitochondrial genes related to respiratory complex, as caused by ectopic expression of chimeric orf 220 gene, which may affect mitochondrial function, although we don't know how this happens.

Functional genes specifically related to pollen development have been well documented till now, of which mutation of any of these genes causes failure of microsporogenesis or abortion of pollen [32-34]. In our study, we observed that many genes related to pollen development were down-regulated in transgenic plants. Furthermore, many same genes in relation to mitochondrial respiratory complex and pollen development were also observed to be down-regulated in transgenic plants and CMS line as well, although we couldn't conclude that these identical down-regulated genes were the causal factor of producing similar phenotype in transgenic plant and CMS line from this study. It is unlikely that mitochondrial proteins alone could directly result in male sterility without a signal transduction from the mitochondria to the nucleus. Such signaling from the mitochondria to the nucleus, termed mitochondrial retrograde regulation, has been well described in yeast and mammals $[19,20]$, although it is less frequently reported in higher plants. Among the clusters of expressed genes in transgenic and WT plants, we also observed several transcriptional factor (TF) genes were induced by ectopic expression of chimeric orf 220 gene, such as, homeobox-leucine zipper family protein (HD-ZIP), DNA/RNA binding protein and zinc finger family protein etc. These TF genes were reported to be involved in the regulation of developmental processes, the response of plants to environmental and redox regulation [35-39]. However, whether these TF genes are associated with mitochondrial retrograde regulation of nuclear gene expression or not need to be further substantiated.

\section{Conclusion}

In conclusion, the mitochondrially-targeted expression of orf220 gene was capable of inducing male sterility in transgenic stem mustard. We proposed that the transformation of orf 220 gene in stem mustard impairs mitochondrial function, and this response is signaled by the mitochondria to nucleus through a particular signal transduction pathway. How the orf 220 gene functions 


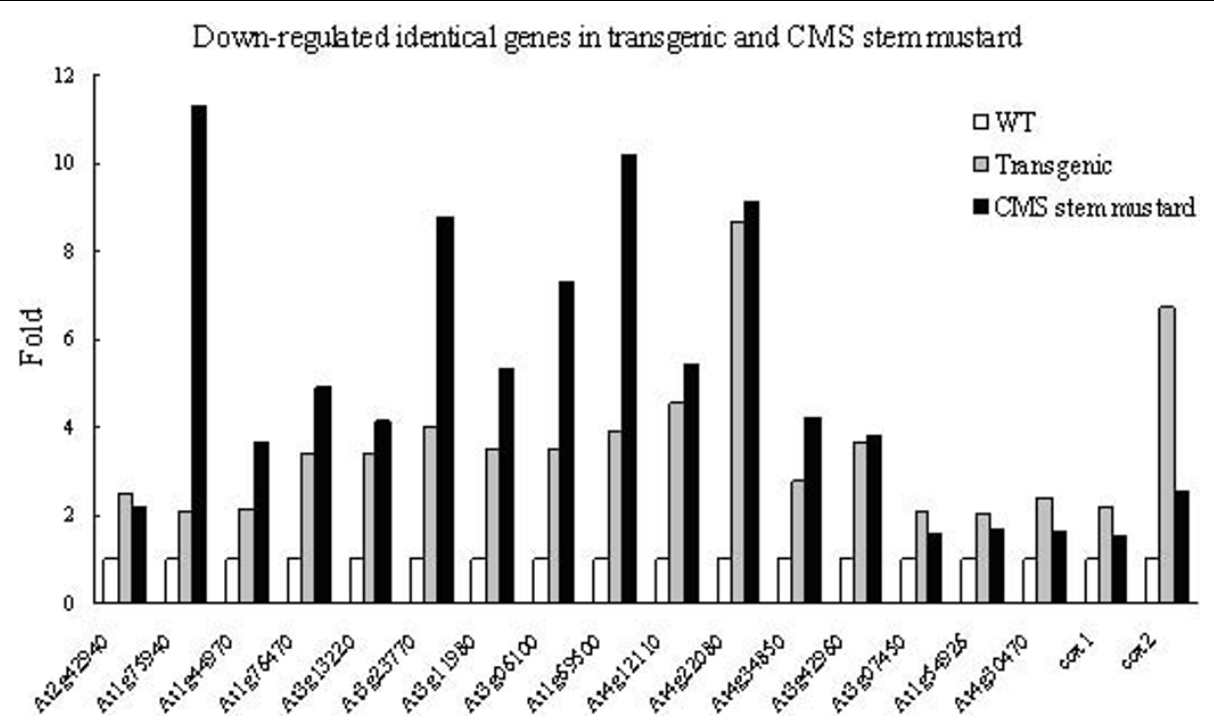

Figure 5 Identical down-regulated genes in transgenic and CMS stem mustard. WT indicates wild type.

precisely to induce male-sterility and its biochemical characterization remains to be discovered. In addition, further research is worthy of being investigate to explore the signal pathway of mitochondrial retrograde regulation and how nuclear target genes are responsive in order, expecially what is the primary receptor gene in the nucleus, if any.

\section{Methods}

Construction and transformation of the chimeric orf220 The candidate CMS-associated orf 220 gene was cloned from CMS stem mustard using a pair of primers in which a $B a m H I$ site was introduced at the $5^{\prime}$ end, and a SacI site at the 3' end. The mitochondrial-targeting sequence (from atp2-1) was amplified from tobacco using primers that introduced an $\mathrm{XbaI}$ site at the ${ }^{\prime}$ ' end and a BamHI site at the 3' end. The mitochondrial transit sequence was the $\mathrm{N}$-terminal 60 amino acid sequence of atp2-1, a peptide which targets proteins foreign to the mitochondria and is cleaved between the $54^{\text {th }}$ and $55^{\text {th }}$ amino acid sites after translocation in transgenic plants $[6,10]$. The procedures used to construct the chimeric gene followed He et al. [6]. This chimeric T-DNA was then transformed into $A$. tumefaciens LBA4404 as

Table 2 Up-regulated expressed genes in transgenic stem mustard observed in this study

\begin{tabular}{|c|c|c|}
\hline Gene ID & Gene Description & Fold \\
\hline At2g02930 & glutathione S-transferase, putative/glutathione S-transferase, putative & 3.03 \\
\hline At2g20900 & diacylglycerol kinase, putative & 2.14 \\
\hline At1g78000 & sulfate transporter (Sultr1;2) & 2.11 \\
\hline At1g32780 & alcohol dehydrogenase, putative & 2 \\
\hline At1g14420 & pectate lyase family protein & 2.12 \\
\hline At1g52940 & calcineurin-like phosphoesterase family protein & 2.11 \\
\hline At1g12240 & beta-fructosidase (BFRUCT4)/beta-fructofuranosidase/invertase, vacuolar & 2.04 \\
\hline At3g14450 & RNA-binding protein, putative & 2.28 \\
\hline At3g19090 & RNA-binding protein, putative & 2.21 \\
\hline At4g25100 & superoxide dismutase (Fe), chloroplast (SODB)/iron superoxide dismutase (FSD1) & 2.57 \\
\hline At4g39940 & adenylylsulfate kinase 2 (AKN2) & 2.06 \\
\hline At3g61890 & homeobox-leucine zipper protein 12 (HB-12)/HD-ZIP transcription factor 12 & 2.13 \\
\hline At5g12000 & protein kinase family protein & 2.48 \\
\hline At5g25560 & zinc finger (C3HC4-type RING finger) family protein & 2.31 \\
\hline At5g20710 & beta-galactosidase, putative/lactase, putative & 2.11 \\
\hline At4g15530 & pyruvate phosphate dikinase family protein & 2.67 \\
\hline
\end{tabular}


described below. A schematic diagram of the chimeric gene vector is shown in Figure 1-A, and the primers used are listed in Table 3.

Proximal portions of hypocotyls from cotyledons obtained from 5-day-old aseptic seedlings were pre-cultured (MS + $3 \mathrm{mg} / \mathrm{L} 6-\mathrm{BA}+0.5 \mathrm{NAA}+3 \%$ sucrose + $0.8 \%$ agar) for 2 days, and subsequently co-cultured with A. tumefaciens containing the chimeric gene in the dark for 2 days on differentiation medium (MS $+3 \mathrm{mg} / \mathrm{L} \mathrm{6-}$ $\mathrm{BA}+0.5 \mathrm{NAA}+3 \%$ sucrose $+0.8 \%$ agar). Shoots were subsequently regenerated for resistance screening from the proximal portions of the cotyledon hypocotyls on differentiation media supplemented with kanamycin $(\mathrm{MS}+3 \mathrm{mg} / \mathrm{L} 6-\mathrm{BA}+0.5 \mathrm{NAA}+20 \mathrm{mg} / \mathrm{L}$ kanamycin $+3 \%$ sucrose $+0.8 \%$ agar). Regenerating shoots $(5 \mathrm{~cm}$ in length) were cut from explants and rooted in the following medium: $1 / 2 \mathrm{MS}+0.1 \mathrm{NAA}+10 \mathrm{mg} / \mathrm{L}$ kanamycin $+3 \%$ sucrose $+0.8 \%$ agar. This regeneration system from stem mustard cotyledons was developed in our laboratory [40].

\section{Construction of GFP fusion vectors and transient expression}

The chimeric atp2-1/orf220 and orf220 coding sequences were amplified from the chimeric vector obtained above using standard protocols with the LA Taq PCR system (Takara, Japan), and using specific primers flanked by Gateway recombination cassettes (Invitrogen, California, USA). The primers used here are listed in Table 3. PCR products were cloned into pDONR221 according to the manufacturer's instructions. Cloning into the final GFP vectors (pK7FWG2) was by LR reaction (Invitrogen, California, USA). The mt-RFP plasmid containing the pre-sequence of Arabidopsis thaliana ATPase delta-prime subunit and DsRed2 was provided by Dr. S. Arimura and Prof N. Tsutsumi (Laboratory of Plant Molecular Genetics, The University of Tokyo) [41].
Biolistic co-transformation of the GFP and RFP fusion vectors was performed on Arabidopsis leaves. In brief, GFP and RFP plasmids (5 $\mu \mathrm{g}$ each) were co-precipitated onto gold particles and transformed using a PDS-100/ He biolistic transformation system (Bio-Rad, http:// www.bio-rad.com). Healthy Arabidopsis leaves were placed on MS medium and bombarded. Leaves were then incubated for $48 \mathrm{hrs}$ at $22^{\circ} \mathrm{C}$ before microscopy using a Nikon fluorescence microscope system.

\section{Phenotypic evaluation of transgenic stem mustard}

Regenerated maintainer lines of stem mustard plants from medium containing kanamycin $(50 \mathrm{mg} / \mathrm{L})$ were treated as putative candidates and were further screened by rooting them on medium containing kanamycin (25 $\mathrm{mg} / \mathrm{L})$. Putative transgenic stem mustard, designated as $\mathrm{T}_{0}$, with normal roots was identified using the orf 220 gene in PCR and RT-PCR analysis. At flowering, they were pollinated with normal pollen from WT plants. Seeds from the $T_{0}$ generation were grown as $T_{1}$ generation and were further identified using the $\operatorname{orf} 220$ gene in PCR and RT-PCR analysis. The primers used in these analyses are listed in Table 3. Transgenic stem mustard plants were observed at flowering time. Seeds were set to study male fertility by self-pollination using a bag covering the flower. Female fertility of transgenic plants was confirmed by pollination with WT pollen.

\section{Pollen morphology and activity evaluation}

The morphology of pollen grains of transgenic and WT stem mustard was examined using a scanning electron microscope (KYKY-1000B). Pollen activity was evaluated using 2,3,5-triphenyl-2h-tetrazolium chloride (TTC) staining, in vitro germination and in-situ germination. In TTC staining, pollen grains were soaked in $0.1 \%$ TTC solution. Active pollen stains red because the NADH/ NADPH produced deoxidizes TTC to TTF (which is red). Pollen in vitro germination was performed at $28^{\circ} \mathrm{C}$

Table 3 Primers used in chimeric expression vector construction

\begin{tabular}{|c|c|c|}
\hline Genes & $\mathrm{F} / \mathrm{R}$ & Primers Sequence $\left(5^{\prime}-3^{\prime}\right)$ \\
\hline \multirow[t]{2}{*}{ orf220 } & F & ATGCCTCAACTGGATAAATTCACTT \\
\hline & $\mathrm{R}$ & TCATCGAAATAGATCGAGGATCTCG \\
\hline \multirow[t]{2}{*}{ Chimeric gene orf 220} & $\mathrm{~F}$ & TACGGATCCATGCCTCAACTGGAT (BamHI) \\
\hline & $\mathrm{R}$ & AGAGAGCTCTCATCGAAATAGATC (Sacl) \\
\hline \multirow[t]{2}{*}{ Chimeric gene atp2-1 } & $\mathrm{F}$ & CCTCTAGACCATGGCTTCTCGGAGGCTTCT (Xbal) \\
\hline & $\mathrm{R}$ & CCGGATCCGCTGCGGAGGTAGCGTACTG (BamH) \\
\hline \multirow[t]{2}{*}{ atp2-1/orf220 GFP } & $\mathrm{F}$ & CACCATGGCTTCTCGGAGGCTTCT \\
\hline & $\mathrm{R}$ & TCGAAATAGATCGAGGATCTCG \\
\hline \multirow[t]{2}{*}{ orf220 GFP } & $\mathrm{F}$ & CACCATGCCTCAACTGGATAAATTCACTT \\
\hline & $\mathrm{R}$ & TCGAAATAGATCGAGGATCTCG \\
\hline
\end{tabular}

Note: underlined italicized nucleotides represent restriction enzyme sites. F, forward; R, reverse. 
and $100 \%$ relative humidity, during which pollen grains were cultured on a liquid medium consisting of boric acid $(250 \mathrm{mg} / \mathrm{L})$ and sucrose $(10 \%)$. Pollen germination success was calculated and photographed after $4 \mathrm{hrs}$ using a microscope (LEICA). To assess in-situ germination, pollen from transgenic and WT plants were placed onto the surface of the stigma and $12 \mathrm{hrs}$ after pollination the pistils were removed and fixed rapidly in FAA fixing solution (ethanol: acetic acid, 3:1) for 2 hrs. The fixed pistils were washed three times with sterile water and treated overnight in softening solution $(8 \mathrm{~mol} / \mathrm{L}$ $\mathrm{NaOH}$ ). The pistils were then washed in distilled water and stained in $0.1 \%$ aniline blue for $3 \mathrm{hrs}$ in the dark. The stained pistils were observed and photographed with a Leica DMRA2 fluorescent microscope.

\section{Oligoarray analysis}

Floral buds of one inflorescence from WT, transgenic stem mustard, and CMS stem mustard were collected to compare the expression of genes during floral development. Bud samples were ground in liquid nitrogen, and total RNAs were prepared using Trizol reagent according to the manufacturer's protocol (Invitrogen). The oligoarrays used in this study were derived from the Arabidopsis thaliana ATH1 chip. All the hybridization procedures and data analysis were performed by CapitalBio Corp. (Bejing, China). Arrays were scanned with a confocal laser scanner, LuxScan ${ }^{\text {tw }} 10 \mathrm{~K}$ (CapitalBio Corp.), and the resulting images analyzed with SpotData Pro 2.0 software (CapitalBio Corp.). Three biological replicates were performed. Differently expressed genes were identified using the $t$-test and multiple test corrections were performed using the False Discovery Rate (FDR) [42]. Genes with an FDR $<0.01$ and a fold change of double or more were considered to be different in gene expression.

For gene annotation, we used the updated TAIR (The Arabidopsis Information Resource) annotation for the Arabidopsis Genome Genechip array http://www.arabidopsis.org and the CapitalBio Corp MAS 2.0 system http://bioinfo.capitalbio.com/mas/. All data were submitted to the CapitalBio Corp MAS 2.0 system http:// bioinfo.capitalbio.com/mas/. Genes were classified into functional categories using Gene Ontology information available from TAIR. The putative pathways were identified through the known pathways in the KEGG database provided by the CapitalBio Corp MAS 2.0 system http:// bioinfo.capitalbio.com/mas/.

\section{Additional material}

Additional file 1: Phenotype of flowering time and alterations on floral development in CMS stem mustard.

Additional file 2: All down-regulated expressed genes detected in transgenic stem mustard
Additional file 3: All up-regulated expressed genes detected in transgenic stem mustard.

\section{Acknowledgements}

This work was supported by a grant from the National Natural Science Foundation of China (NSFC30800749) and a grant from ZJNSF (Y3080082). We thank Prof. Mikio Nakazono, Prof. Rosine. de Paepe and Prof. Sally A. Mackenzie for providing critical comments on the paper. We thank Dr. Shinyichi Arimura for offering mitochondrially-targeted RFP and assistance in using the Laser Scanning Confocal Microscope.

\section{Author details}

${ }^{1}$ Laboratory of Genetic Resources \& Functional Improvement for Horticultural Plants, Department of Horticulture, Zhejiang University, Hangzhou, 310029, P. R. China. ${ }^{2}$ Laboratory of Horticultural Plant Growth, Development \& Quality Improvement, Ministry of Agriculture, Hangzhou, 310029, P. R. China.

\section{Authors' contributions}

JHY constructed the chimeric orf220 gene and transformed it to WT stem mustard. XYL carried out the localization of the chimeric orf220 gene. JHY and XDY analyzed the phenotype and pollen activity. The oligoarray experiment and analysis were proceeded at CapitalBio Corp. Beijing China. JHY wrote the paper. MFZ edited the paper. All the authors read and approved the final manuscript.

Received: 11 May 2010 Accepted: 26 October 2010

Published: 26 October 2010

\section{References}

1. Schnable PS, Wise RP: The molecular basis of cytoplasmic male sterility and fertility restoration. Trends in Plant Sci 1998, 3:175-180.

2. Budar F, Pelletier G: Male sterility in plant: occurrence, determinism, significance and use. Life Sci 2001, 324:543-550.

3. Hanson MR, Bentolila S: Interaction of mitochondrial and nuclear genes that affect male gametophyte development. Plant Cell 2004, 16(Suppl):154-S169.

4. Linke $B$, Börner $T$ : Mitochondrial effects on flower and pollen development. Mitochondrion 2005, 5:389-402.

5. Yang JH, Zhang MF: Molecular genetics of mitochondrial respiratory/ATPrelated genes in relation to cytoplasmic male-sterility of higher plants. Gene Genomes and Genomics 2007, 1:21-26.

6. He S, Abad AR, Gelvin SB, Mackenzie SA: A cytoplasmic male sterilityassociated mitochondrial protein causes pollen disruption in transgenic tobacco. Proc Natl Acad Sci USA 1996, 93:11763-11768.

7. Wang ZH, Zou YJ, Li XY, Zhang QY, Chen L, Wu H, Su DH, Chen YL, Guo JX, Luo D, Long YM, Zhong Y, Liu YG: Cytoplasmic male sterility of rice with boro II cytoplasm is caused by a cytotoxic peptide and is restored by two related PPR motif genes via distinct modes of mRNA silencing. Plant Cell 2006, 18:676-687.

8. Kim DH, Kang JG, Kim BD: Isolation and characterization of the cytoplasmic male sterility-associated orf456 gene of chili pepper (Capsicum annuum L.). Plant Mol Biol 2007, 63:519-532

9. Yamamoto MP, Shinada H, Onodera Y, Komaki C, Mikami T, Kubo T: A male sterility-associated mitochondrial protein in wild beets causes pollen disruption in transgenic plants. Plant J 2008, 54:1027-1036.

10. Chaumont F, Bernier B, Buxant R, Williams M, Levings CS, Boutry M: Targeting the maize T-urf13 product into tobacco mitochondria confers methomyl sensitivity to mitochondrial respiration. Proc Natl Acad Sci USA 1995, 92:1167-1171.

11. Wintz H, Chen HC, Sutton CA, Conley CA, Cobb A, Ruth D, Hanson MR: Expression of the CMS-associated urfs sequence in transgenic petunia and tobacco. Plant Mol Biol 1995, 28:83-92.

12. Duroc $Y$, Gaillard $C$, hiard S, Tinchant $C$, Berthomé $R$, Pelletier G, Budar F: Nuclear expression of a cytoplasmic male sterility gene modifies mitochondrial morphology in yeast and plant cell. Plant Sci 2006, 170:755-767. 
13. Sabar $M$, Gagliardi $D$, Leaver $C$ : OrfB is a subumit of $F_{1} F_{0}$-ATP synthase: insight into the basis of cytoplasmic male sterility in sunflower. $E M B O$ Rep 2003, 4:382-386.

14. Chase CD: Cytoplasmic male sterility: a window to the world of plant mitochondrial-nuclear interactions. Trends in Genet 2007, 23:81-90.

15. Rhoads DM, Subbaiah CC: Mitochondrial retrograde regulation in plants. Mitochondrion 2007, 7:177-194

16. Carlsson J, Leino M, Sohlberg J, Sundstroem JF, Glimelius K: Mitochondrial regulation of flower development. Mitochondrion 2008, 8:74-86.

17. Woodson JD, Chory J: Coordination of gene expression between organellar and nuclear genomes. Nat Reviews Genet 2008, 9:383-395.

18. Yang $J H$, Zhang MF: Mitochondrial retrograde regulation tuning fork in nuclear genes expressions of higher plants. J Genet and Genomics 2008, 35:65-71.

19. Butow RA, Avadhani NG: Mitochondrial signaling: the retrograde response. Mol Cell 2004, 14:1-15.

20. Liu ZC, Butow RA: Mitochondrial retrograde signaling. Annu Rev Genet 2006, 40:159-185.

21. Zubko MK, Zubko E, Ryban AV, Adler K, Mock HP, Misera S, Gleb YY, Grimm B: Extensive development and metabolic alteration in cybrids Nicotiana tabacum (+Hyoscyamus niger) are caused by complex nucleuscytoplasmic incompatatibility. Plant J 2001, 25:627-639.

22. Linke B, Nothnagel T, Börner T: Flower development in carrot CMS plant: mitochondria affect the expression of MADS box genes homologous to GLOBOSA and DEFICIENS. Plant J 2003, 34:27-37.

23. Meguro A, Takumi S, Ogihara Y, Muria K: WAG, a wheat AGAMOUS homolog, is associated with development pistil-like stamens in alloplasmic wheat. Sex Plant Reprod 2003, 40:167-177.

24. Hama E, Takumi S, Ogihara Y, Murai K: Pistillody is caused by alteration to the class-B MADS-box gene expression pattern in alloplasmic wheat. Planta 2004, 218:712-720.

25. Teixeira RT, Farbos I, Glimelius K: Expression levels of meristem identity and homeotic genes are modified by nuclear- mitochondrial interactions in alloplasmic male-sterile lines of Brassica napus. Plant J 2005, 42:731-742.

26. Yang JH, Zhang MF, Yu JQ: Relationship between cytoplasmic male sterility and SPL-like gene expression in stem mustard. Physiol Plant 2008, 133:426-434.

27. Carlsson J, Lagercrantz U, Dundström J, Teixeira R, Wellmer F, Meyerowitz EM, Glimelius K: Microarray analysis reveals altered expression of a large number of nuclear genes in developing cytoplasmic male sterile Brassica napus flowers. Plant J 2007, 49:452-456.

28. Fujii S, Komatsu S, Toriyama K: Retrograde regualtion of nuclear gene expression in CW-CMS of rice. Plant Mol Biol 2007, 63:405-417.

29. Xu P, Yang YM, Zhang ZZ, Chen WH, Zhang CQ, Zhang LX, Zou SX, Ma ZQ: Expression of the nuclear gene $\operatorname{TaF}(\mathrm{A})$ is under mitochondrial retrograde regulation in anthers of male sterile wheat plants with timopheevii cytoplasm. J Exp Bot 2008, 59:1375-1381.

30. Zhang MF, Chen LP, Wang BL, Yang JH, Chen ZJ, Yutaka $H$ : Characterization of atpA and orf220 genes distinctively present in cytoplasmic male-sterile line of tuber mustard. J Hort Sci Biotechnol 2003, 78:837-841.

31. Yang $J H$, Huai $Y$, Zhang MF, Yu JQ: Mitochondrial atpA gene is altered in a new orf220-type cytoplasmic male-sterile line of stem mustard (Brassica juncea). Mol Biol Rep 2009, 36:273-280.

32. Becker JD, Boavida LC, Carneiro J, Haury M, Feijo JA: Transcriptional profiling of Arabidopsis tissues reveals the unique characteristics of the pollen transcriptome. Plant Physiol 2003, 133:713-725.

33. Honys D, Twell D: Comparative analysis of the Arabidopsis pollen transcriptome. Plant Physiol 2003, 132:640-652.

34. Ma H: Molecular genetic analyses of microsporogenesis and microgametogenesis in flowering plants. Annu Rev Plant Biol 2005, 56:393-434.

35. Carabelli M, Sessa G, Baima S, Morelli G, Ruberti I: The Arabidopsis Athb-2 and -4 genes are strongly induced by far-red-rich light. Plant J 1993, 4:469-479.

36. Schena M, Lloyd AM, Davis RW: The HAT4 gene of Arabidopsis encodes a developmental regulator. Genes Dev 1993, 7:367-379.

37. Chan RL, Gago GM, Palena CM, Gonzalez DH: Homeoboxes in plant development. Biochim Biophys Acta 1998, 1442:1-19.
38. Shin D, Koo YD, Lee JY, Lee HJ, Baek DW, Lee SC, Cheonc C, Kwak SS, Lee SY, Yun DJ: Athb-12, a homeobox-leucine zipper domain protein from Arabidopsis thaliana, increases salt tolerance in yeast by regulating sodium exclusion. Bioch Biophys Res Commun 2004, 323:534-540.

39. Tron AE, Bertoncini CW, Chan RL, Gonzalez DH: Redox regulation of plant homeodomain transcription factors. J Biol Chem 2002, 277:34800-34807.

40. Chen LP, Zhang MF, Hirata Y, Cao JS, Chen JZ: Efficient plant regeneration from cotyledon-derived protoplasts of cytoplasmic male-sterile tube mustard (Brassica juncea Coss. Var tumida Tsen et Lee). Acta Phytophysiologia Sinica 2001, 27:437-440.

41. Arimura S, Tsutsumi N: A dynamin-like protein (ADL2b), rather than FtsZ, is involved in Arabidopsis mitochondrial division. Proc Natl Acad Sci USA 2002, 99:5727-5731.

42. Benjamini $Y$, Hochberg $Y$ : Controlling the false discovery rate: a practical and powerful approach to multiple testing. J Roy Statist Soc Ser B 1995, 57:289-300.

doi:10.1186/1471-2229-10-231

Cite this article as: Yang et al: Mitochondrially-targeted expression of a cytoplasmic male sterility-associated orf220 gene causes male sterility in Brassica juncea. BMC Plant Biology 2010 10:231.

\section{Submit your next manuscript to BioMed Central and take full advantage of:}

- Convenient online submission

- Thorough peer review

- No space constraints or color figure charges

- Immediate publication on acceptance

- Inclusion in PubMed, CAS, Scopus and Google Scholar

- Research which is freely available for redistribution

Submit your manuscript at www.biomedcentral.com/submit
Biomed Central 